\title{
ON THE USE OF SYSTEMS TECHNOLOGIES AND A SYSTEMATIC APPROACH FOR THE SYNTHESIS AND THE DESIGN OF FUTURE
} BIOREFINERIES †

\author{
Antonis C. Kokossis ${ }^{1, *}$, Aidong Yang ${ }^{2}$ \\ ${ }^{1}$ School of Chemical Engineering, National Technical University of Athens, Greece \\ ${ }^{2}$ Division of Civil, Chemical, and Environmental Engineering, Faculty of Engineering \\ and Physical Sciences, University of Surrey, UK
}

Abstract

Systems technologies emerge with a powerful potential to support the deployment and design of future biorefineries. The chemical industry experiences a steady growth in the use of renewables induced by the gradual depletion of oil, uncertainties in energy supplies and a commanding requirement to reduce GHG emissions and save the planet. Renewables introduce an impressive range of options with biorefining at the centre of attention as an emerging industrial concept, uniquely attached to chemical engineering and aiming to transform plant-derived biomass into a variety of products including transport fuels, platform chemicals, polymers, and specialty chemicals. In competing with conventional processes, biorefineries should match maximum efficiencies with better design and process integration. The paper highlights the pivotal role of systems technology to foster innovation, preview options, and support high-throughput computational experimentation, arguing that systems tools are largely under-deployed. Systems-enabled platforms could instead function as powerful environments to generate ideas for integrated designs and offer tremendous services to the complex and large problems produced by the numerous portfolios of feedstocks, unknown portfolios of products, multiple chemistries, and multiple processing paths. Complexities certainly exceed capabilities of previous methodologies but

\footnotetext{
${ }^{\dagger}$ Published in: Computers and Chemical Engineering 34(9):1397-1405.

${ }^{*}$ To whom all correspondence should be addressed.
} 
established achievements and experience with similar problems are excellent starting points for future contributions. Besides a general discussion, the paper outlines opportunities for innovation in design, concept-level synthesis, process integration, and the development of supply chains.

Keywords Renewables, Biorefineries, Process Synthesis, Process Integration, Optimization.

\section{Introduction}

Apart from frequent and irregular changes in the costs and profit margins, the chemical industry faces the discomforting aspect that its major types of feedstock will deplete in the foreseeable future. The industry remains highly dependent on oil and gas (80\% of its feedstock and energy according to Eurostat) with oil reserves to probably last for only 40 years and natural gas for 60 years (BP, 2008). As only 50\% of the reserves are classified as conventional, the exploration and the processing of the remaining $50 \%$ may be hiding unattractive margins. The first decade of the 21 st century is witnessing a drive towards sustainable manufacturing, GHG reductions and the increasing use of renewable resources. From an environmental perspective, the chemical industry has made significant efforts to improve its energy efficiency. However, fossil-oil transportation fuels are major products of the industry that continue to contribute heavily to GHG emissions. consuming nearly $25 \%$ of the total net primary energy and $70 \%$ of the energy provided by petroleum and NGPL (EIA, 1999). In EU alone, in the period from 1990 to 2010 about $90 \%$ of CO2 emissions will be attributable to transport (BRAC, 2006). From a sustainability perspective, $80 \%$ of transportation fuels originate from petroleum sources (Laurence Livermore National Laboratory, 2004) and oil depletion is setting an exceptional challenge on transportation.

Biomass offers a promising alternative to the needs of modern society, already providing $13 \%$ of the world energy needs (IEA Statistics 2005). With most of its annual production left underexploited (220 billion tones per year),biomass accounts for the only renewable source of carbon-based fuels. In 2007 figures (USA) biomass tops renewable energy consumption (53\%) ahead of hydroelectric power (35\%), wind energy (5\%) and solar energy (1\%).Motivated by the need for sustainable solutions and general uncertainties in oil prices and energy supplies, the industry has been experiencing a steady growth in the production of biofuels (Demirbas, 2006; Huber et al, 2006) that is now developing into the emerging concept of biorefining (Fernando et al., 2006; Clark, 2007). Biofuels offer access to a wide range of chemicals that include oxygenates (methanol, ethanol, butanol, mixed alcohols, dimethyl-ethers) and hydrocarbons (biodiesel, synthetic diesel, synthetic gasoline and methane). Biorefining bears striking analogies with fossil-oil refining, fractionating biomass into a family of products to include transport fuels, platform chemicals, polymers, and specialty chemicals with yields and distributions that vary widely on the chemical and physical nature of the feedstock. With the production concentrated on 
biofuels, oil refining remains more viable as every drop of oil is used to make commodities (fuels, bulk chemicals) and specialty chemicals. Following the example of the petroleum industry, sustainable multiple product biorefineries should target a greater proportion of biomass, producing multiple streams of high volume/low value as well as low volume/high value molecules (Audsley and Annetts, 2003). Looking into the near future, the expected annual growth rate for fermentation products is $5 \%$ (compared to $2-3 \%$ for the overall chemical production) with McKinsey (Riese, 2006) predicting that by 2010 biobased products will account for $10 \%$ of the chemical industry (96€ billion).

From a systems perspective, the design and the synthesis of biorefineries are open and complex problems as biorefineries, to compete with conventional processes, should achieve maximum efficiencies with better design and process integration. Dimian (2007) discusses opportunities for computer-aided process engineering and renewable raw materials, particularly with regard to conceptual process design. Klatt and Marquardt (2008) highlighted the processing of renewable feedstocks as one of the emerging application domains in process systems engineering. First generation biofuels proved that using plant material does not necessarily improve sustainability. Accordingly, the development of biorefineries has to follow a holistic approach, with new challenges to account for the wide range of feedstocks and a need to formulate local and regional patterns of solutions. Unlike the case of fossil oil and gas as they are produced and processed on a global basis, the sustainable utilization of biomass requires a production close to, and closely integrated with, their source. Biorefineries will then probably take the form of regional developments designed to best exploit resources and regional forms of renewable energy, following paradigms of Industrial Symbiosis (Chertow, 2004).

The remaining sections review developments in the first and the second generation of biofuels, systems challenges in the optimization of their supply chains, and a position that the total systems approach could seize a chance for major and lasting contributions. In each section, the paper highlights opportunities to apply or develop systems methods, arguing that the systems technology is the natural approach to produce solutions for the complex problems posed by biorefineries.

\section{Early developments in the production of biofuels}

\subsection{Achievements of first generation refineries}

Early efforts in the production of biofuels established, quite separately, biochemical and thermochemical routes (cf. Figure 1) characterized by a focus on the production of a single biofuel and the use of food-based sources as feedstock. The biochemical paths addressed transportation fuels and included fermentation and extraction paths based on edible agricultural products. As fermentation requires sugars, sugar canes have been primal choices leading to Brazil's gasohol program. In USA, a long history of corn-based bioethanol technology, previously unable to compete with cheaper petroleum prices, has experienced a revival, especially in the grain growing states of Midwest. Using plant oils and 
transesterification with methanol, Europe shifted towards the production of biodiesel (fatty acid methyl ester) bringing substance, with over 400 outlets selling biodiesel in Germany, to an old claim by Rudolf Diesel that his 'engines can be fed with vegetable oils helping the agriculture of the countries that use it'. At a limited scale, also using a biochemical path, biogas and LFG gases, essentially byproducts of waste management, increasingly contributed to the generation of power and heat. However, a wider production of heat and electricity is available using thermochemical technology to produce gaseous fuels (and charcoal) and run gas turbines and engines, using a large variety of biomass and waste. Such technologies tread well-known paths of combustion, gasification (Fisher-Tropsch), and pyrolysis, also bringing to the fore possibilities to integrate gasification with pyrolysis, and chemical routes with thermochemical products (synthesis gas, methanol, hydrogen, diesel, bio-oil).

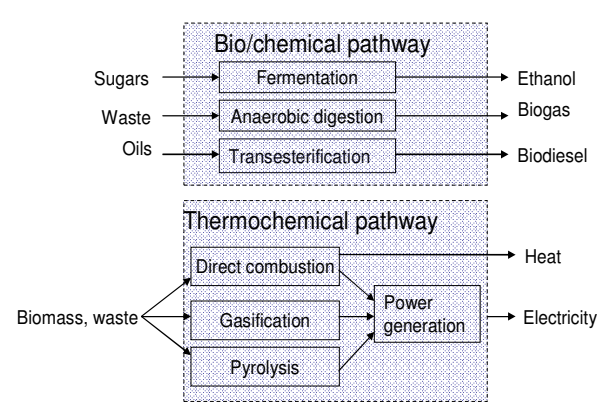

Figure 1. Early developments of biofuels

\subsection{The systems perspective}

From a systems perspective, biorefineries represent ordered combinations of feedstocks, processing pathways, processing technologies, and products. At least in reference to the biochemical transformations, early developments actually addressed a limited number of biofuel products (mainly ethanol and biodiesel), well-known processing pathways, a limited number of processing technologies, and a variety of different feedstocks. Still, systems technology had on offer powerful methods to systematize improvements, upgrade flowsheets, target the performance of processing units, achieve better flowsheet integration, and assess the impact of seasonality and variability of the feedstocks.

Concerning sugar based processes, NREL (McMillan, 2006) has emphatically explained the need to use process integration and study strong trade-offs between pre-treatment, fermentation and sacharification (feed conditioning, selection of pretreatment and use of acids, selection of reactors, choices and conditions of intermediates, integration of reaction and separation), all leading to challenging and interesting problems in optimization and synthesis . In biodiesel processes, similar challenges relate to the selection of pretreatment stages, the design and the selection of reactors and reaction conditions, and the potential to integrate adjacent processes (i.e. reaction and separation). Thermochemical paths 
offer more aggressive routes to energy (through higher temperatures) and alternative processes to use (gasification, pyrolysis, methanol synthesis, Fischer-Tropsch), with some processes still developing (especially the ones involving catalysis) and others already developed. Aside an apparent interest in new developments, an equally interesting aspect is the appropriate selection and integration of the available technologies. Superstructure methods could have supported, for instance, a systematic screening of technological options for the pre-treatment stages or a rigorous assessment of performance limits for reactors and separators. Multi-period optimization models could have systematically assessed the variability in raw materials and compositions, whereas Pinch Analysis could have determined quick targets for energy and water use, setting incentives for better integration.

Targeting methods hold an indispensable and critical role in these developments, offering techniques to quickly assess the scope to integrate ahead of detailed designs. Such methods are plentiful on energy targeting (Gundersen, 1988; Briones and Kokossis, 1999a,b), water targeting (Wang and Smith, 1994a,b; Smith, 2005; Hallale and Fraser, 1998; Alva-Argaez et al., 1999; 2007a,b; Gunaratnam et al., 2005), and mass-exchange networks (Halwagi, 1997, 1990a,b, 2006, 2008), but also in reactor and reaction engineering targeting (Halwagi and Srinivas, 1992; Marcoulaki and Kokossis, 1999; Mehta and Kokossis, 1997, 1998; Kokossis and Floudas, 1990), simple and complex distillation (Shah and Kokossis, 2001, 2002), solvent design (Papadopoulos and Linke, 2006a, b; Kazantzi et al., 2007, Kazantzi and Halwagi, 2005; Marcoulaki and Kokossis, 2000, 2001) and reaction-separation systems (Linke and Kokossis, 2003a,b, 2004, 2007; Kokossis and Floudas, 1991). Instead, literature evidence indicates a predominant use of general flowsheeting technology for techno-economic and case-by-case analysis, using Aspen Plus for instance, as in the work of NREL on bioethanol production (Wooley et al, 1999) and that of Haas et al. (2006) for biodiesel.

In reference to thermochemical processes, the use of systems technology tools is similarly restricted to general flowsheeting and CFD modeling, as in the work of pyrolysis reactors (Bridgwater et al., 1999; Wurzenberger et al., 2007; Blasi, 2008) where the emphasis is on the simulation and the validation of experimental results. The design of conversion units, essentially reactors, remains at the heart of the design (Smith, 2005) but the useful application of CFD technology requires guidance and will have to be coordinated by process synthesis. Otherwise, at this stage of biorefinery developments, CFD applications will remain with very limited scope to contribute. Even though consistently praised as important, the integration between different processing routes is unnoticeable in the literature with processing paths on Figure 1 essentially studied in isolation. Systematic approaches certainly missed a chance for better contributions due to a number of reasons, not excluding a lack of awareness or confidence by the practice groups for the advanced systems methods available. 


\section{Second generation fuels and multi-product biorefineries}

\subsection{Characteristics of second generation refineries}

While the production of first generation biofuels continues to increase, its sustainability and viability remain uncertain and questionable. The viability depends on world prices for sugar, grains and oil, all of which have varied widely and rapidly over the years. Major concerns relate to the sustainability of production, as feedstocks compete with food supplies whereas processing of low-density biomass yields excessive requirements for land. Focused on sugars and starch, the production neglects the energy-rich cellulosic and lignocellulosic content that, although more difficult to process, accounts for a larger portion of the biomass available.

Second generation $(2 \mathrm{G})$ biorefineries advocate a whole crop approach, featuring additional processing paths for residues and leading to complex portfolios of multiple products (biofuels and specialty chemicals), drawing direct analogies to conventional refineries (Fernando et al., 2006; Clark, 2007). The range of suitable feedstocks is much larger whereas the additional processing paths may separately follow either the biochemical or the thermochemical conversions discussed earlier. Biochemical conversions, as illustrated in Figure 2, make repeated use of enzyme technology to produce, not only C6 and C5 sugars required for the cellulosic ethanol, but numerous intermediate fractions in the form of carbohydrates, proteins, and phenolics. Several intermediates in the form of oligomers and monomers account for potential building blocks in the production of specialty chemicals, organic acids and polyols, natural 'health food' components (phytosterols, folates, phytates), prebiotics, and additives. Engineering yields and efficiencies are subject to continuous improvements using better enzyme technologies and catalytic processes. Lignocellulosic biomass, still difficult to break with enzyme technology, is processed thermochemically for either heat (or power), or to produce chemicals (methanol, synthetic diesel, bio-oil). 2G biodiesel combines gasification with syngas and FT synthesis to also produce LPG, naphtha, jet oil and lubricants. Hydrogenation of plant oils to 'green diesel' yields fuels with superior energy and GHG properties over conventional biodiesel. 


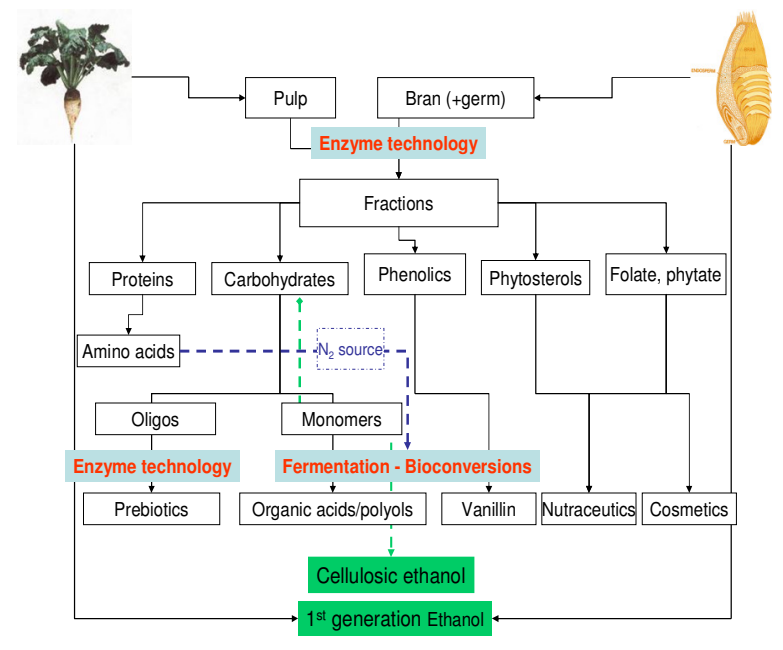

Figure 2. Biochemical conversions in $2 G$ biorefineries (courtesy of INRA)

In comparison with first generation biofuels, $2 \mathrm{G}$ biorefineries involve an extensive number of possible products, numerous processing paths, and extensive options for processing technologies. Figure 3 illustrates the case in the processing of lignocellulosics.

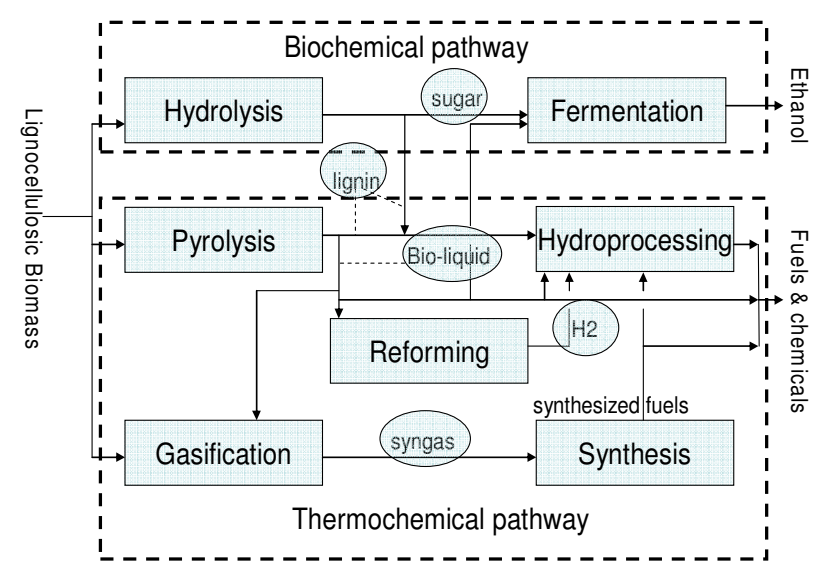

Figure 3. Processing routes in lignocellulosics (adapted from Bridgwater, 2007)

\subsection{Systems technologies - the pivotal roles of process synthesis and process integration}

Design considerations for second generation biorefineries lead to decision-making problems that are complex and large, bringing into relation all known scales of process development. Systems technologies emerge with capabilities to systematize the analysis and contribute towards the development of innovative solutions. Adjusted from an internal report of the pioneering Process Integration Research Center at the University of Manchester, the hierarchical cascade of Figure 4, presents the information flows between systems technologies and the commanding role of process synthesis and process 
integration (Kokossis, 1993). Given an abundance of degrees of freedom for processing paths and products, synthesis and process integration are instrumental to coordinate a concept-based level analysis (strategic decisions), ahead of detailed evaluations and flowsheeting studies. Thermodynamics, targeting and shortcut methods bring insights particularly useful to simplify the problem. Concerning the integration of pathways, separate challenges exist for assessing feedstocks (Gulati et al., 1996) and processing paths. Then, the systems approach could support a holistic evaluations of techno-economic tradeoffs and objectives determining robust portfolios of products to match market uncertainties, process uncertainties and variable feedstocks. The development of effective and economical synthesis representations is a major challenge, as exhaustive superstructures are highly unlikely to bear fruitful results in such large and complex problems.

Figure 4 further provides the basis to systematically assess new technologies and re-engineering initiatives. Technologies may relate to emerging reaction and processing paths (promising enzymes, catalysts, chemistries etc) whereas re-engineering may address existing installations (i.e. paper industries, existing refineries) re-engineered into biorefineries. Cascade flows of Figure 4 imply a coordinated effort where existing processes (blocks on the right) are modeled and upgraded with the induction of new products and paths (process synthesis search), selected ideas are integrated into the process (process integration search) and then simulated to assess sustainability and environmental conformance (sustainability analysis). Following the links of Figure 4, the cascade would have to repeat this cycle several times before any selected processes are demonstrated and implemented.

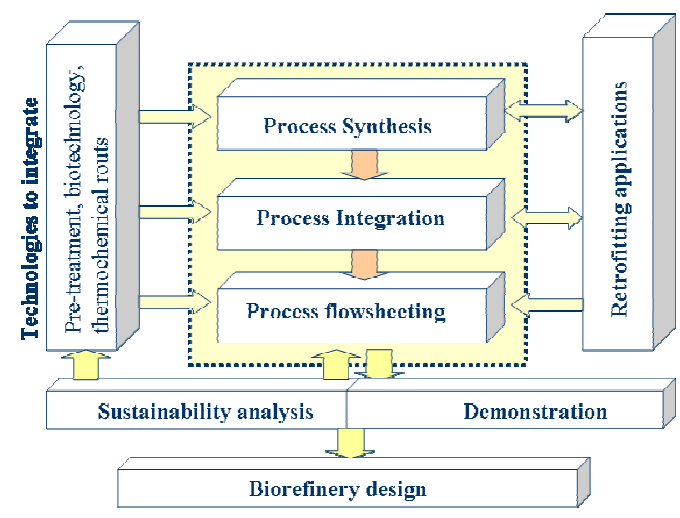

Figure 4. Roles of systems tools in the design of biorefineries.

\subsubsection{Biorefinery design with a systematic approach}

A systematic design effort has been set in BIOCORE, one of three major EU-funded projects to develop multi-product biorefineries in Europe. BIOCORE has adopted the layered structure of Figure 4 having secured a large consortium of 
experimental groups that make available pre-treatment, biochemical and thermochemical technologies. Sketched in Figure 5, the biorefinery comprises a single section for the primary biorefinery with two additional sections devoted to biotechnology and thermochemical routes. The primary biorefinery produces candidate blocks possible to process towards unknown portfolios of products and through an equally unknown level of integration between and/or within different sections. Synthesis and integration play a pivotal role in the developments. In the primary biorefinery, synthesis methods are useful to scope for useful products (P1-P4) and function blocks as well as to integrate and optimize pre-treatment processes. In the biotechnology section, synthesis has to scope for alternative paths (R1-R4), alternative chemical blocks (X1-X3) and options for different processing routes (I1-I4). There is a long list of possible biofuels and bio-products to choose from and they are all degrees of freedom in the problem. In the thermochemical section, there are separate portfolios of products (Y1-Y6), separate chemical blocks (X1-X3) and attractive options for integration with the biotechnology section. Adding to the complexity, the development has to consider a variety of feedstocks (poplars, SRCs, agricultural waste) featuring significant differences in physical properties and composition. Simple, unprepared efforts that make use of off-the-shelf methods (i.e. exhaustive superstructures, ready-made models) will fall short to foster innovation. Instead, research has to produce a new generation of tools tailored to handle the size and the complexity of the new problems.

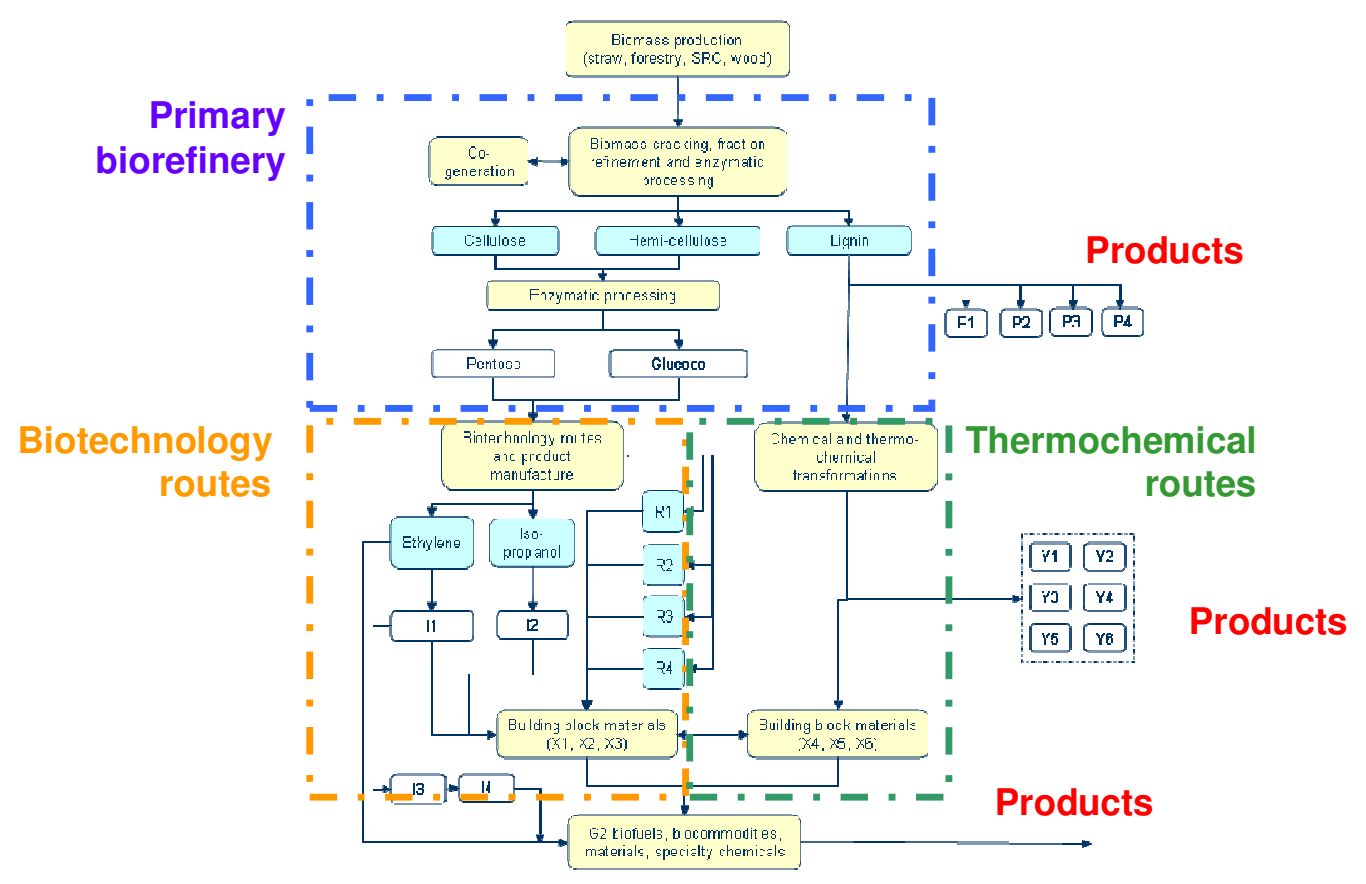

Figure 5. Designing a comprehensive biorefinery: an EU example. 


\subsection{2 'Retrofitting' the petrochemical refineries}

The integration of biomass processing is an attractive way to upgrade conventional refineries and represents a modern systems version of a retrofit problem. Examples include the production of 'green biodiesel', the NexBTL process, and the catalytic cracking of pyrolytic lignin (CGR, 2008). Green biodiesel (Petrobras/H-BIO, UOP with ENI) is produced widely with the hydrogenation of plant oils (or animal fat) using hydrogen available at the refinery. Fortum Oil Oy uses the proprietary NExBTL process to produce an isoparaffinic fuel (not FAME) still compatible with existing diesel engines (capacities range from 170-800 kT/yr). The hydrotreating and catalytic cracking of pyrolytic lignin (UOP, 2005) produces gasoline and aromatics, reforming further the water-soluble phase of bio-oil to produce hydrogen. The systematic development of such integrated scenarios could use a systems approach to differentiate between available feedstocks (biomass and fossil), processing routes (biomass, petrochemical refinery), and available chemicals. This comparator could produce scenarios for integration badly needed in reviewing the numerous options available in practice.

Starting in 2009, a collaborative project supported by DEFRA (UK) is specifically committed to deploying a systems platform for this purpose with a focus on developments of the Teesside industrial complex at the North East of England. In particular, this platform is to be used to identify the best solutions for combining biomass processing routes with conventional feedstock processing facilities to produce bulk chemicals. Reflecting the industrial interests of this region, these chemicals include methanol, ethanol, butanol, ethylene, propylene glycol, acetone, styrene, and ammonia. A broad range of biomass processing technologies are considered, including both bio/chemical routes such as fermentation, anaerobic digestion, and transesterification, and thermochemical routes such as pyrolysis and gasification. These biomass processing routes are to be combined with conventional petrochemical technologies such as synthesis, conversion, treating, cracking, and reforming. This will generate candidates for viable scenarios where biomass-derived intermediate products join retrofitted conventional processing chains. The ultimate goal of this is to produce energy and chemical products in a way which reduces the dependency on nonrenewable feedstock and is both economical and environmental-friendly.

The basic methodology adopted in this project is illustrated by Figure 6. On the left shows schematically a superstructure that represents the possible combinations of conventional and bio-based feedstock and processing units for producing a set of desired products (P1-P3). A possible result of optimization is shown on the right hand side, in the form of a configuration that involves optimal feedstock and processing options. 

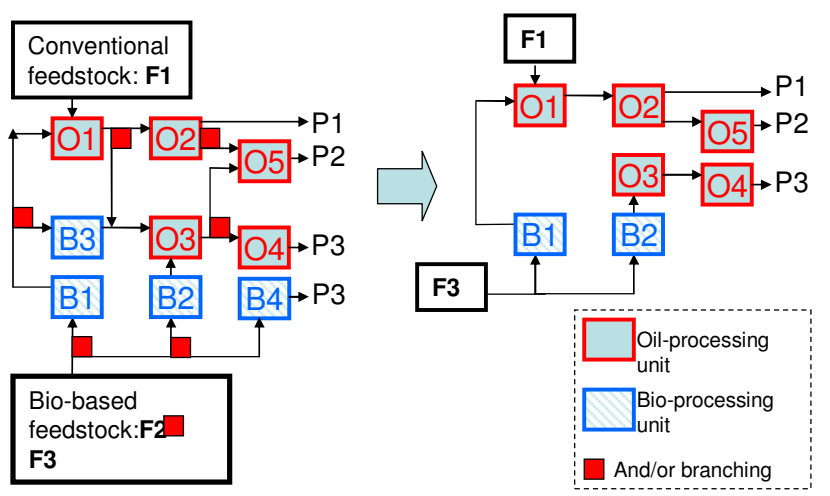

Figure 6. Methodology for retrofitting petrochemical refineries.

\subsubsection{Process level analysis and research}

Separate efforts have addressed the improvement of process units and especially reactors, as in the work of cellulosic hydrolysis (Zhang and Lynd, 2004), and the integration of fermentation with hydrolysis. Using alternative reactors and better integration, and in reference to a base case stirred-tank reactor, NREL reported a two-fold increase in the concentration of sugars, a ballpark figure for the expected benefits in the yields. Instead of case-by-case analysis, systems tools are able to, systematically target efficiencies (Mehta \& Kokossis, 1997, 1998; Marcoulaki \& Kokossis, 1999), setting the scope for integration El-Halwagi, 1997, 2006; Linke \& Kokossis, 2007, El-Halwagi, et al., 2008) and enabling the evaluation of fractionation, enzyme technologies and reactive-separation schemes (Linke \& Kokossis, 2003a). Flowsheeting and simulation studies certainly dominate the literature, as in the work of Cardona and Sanchez (2006) that used Aspen Plus to evaluate process configurations in the production of ethanol from lignocellulosic biomass. Configurations experimented with different arrangements for hydrolysis, fermentation and purification, and several scenarios for water recycle. Using alternative simulators, Pfeffer et al. (2007) evaluated the energy demand over several options to utilize tillage. Piccolo and Bezzo (2008) simulated the production of lignocellulosic ethanol comparing fermentation routes with enzymatic hydrolysis over gasification. Gutierrez et al. (2009) simulated scenarios to integrate biodiesel production from palm oil with ethanol produced from lignocellulosic residues of the plant. In comparison to flowsheeting analysis, synthesis and process integration applications are rare but exist. Duret et al. (2005) applied energy integration to study the gasification of wood in the production of synthesis gas. Sanchez et al. (2006) provide a synthesis study for the production of lignocellulosic ethanol. More recently, Gassner and Marechal (2008a, b) optimized wood gasification processes enabling the possible integration with electrolysis and producing promising flowsheets for validation, setting the type of screening expected from the synthesis and process integration methods. 


\section{Challenges in the Design of Supply Chains}

The selection of processing technologies depends not only on the production costs and the value of the biorefinery products, but also on the supply chains required and the business models available. The development of viable business models is a challenging and difficult problem with several dimensions. Biomass resource systems have to match the quality characteristics of existing distribution systems but, due to the bulky nature of biomass, road transportation affects carbon and energy balances and is expensive in relation to the product value.

Several literature studies demonstrate optimization models that combine processing and transportation costs in the supply chains of renewables-based manufacturing, using mathematical programming to illustrate techno-economic tradeoffs between production and logistics. In the production of bioethanol from sugar cane and sweet sorghum, Nguyen and Prince (1996) optimized transportation costs and the scale of the production plant. Using a variety of lignocellulosic feedstocks, Kaylen et al. (2000) optimized the location and the capacity of feedstocks to maximize bioethanol and furfural production. Recent studies evaluate product portfolios, as in the work of Sammons et al. (2007) that optimized the allocation of biorefinery products accounting for sales revenues, processing and feedstock costs. The demonstration included the production of syngas from chicken litter with syngas allocated between hydrogen and electricity stations. In reference to wheat bran and wheat-based biorefineries, Sadhukhan et al. (2008) reported a comparable value analysis approach that models marginal contributions from processing routes and products and compares different manufacturing scenarios.

Instead of the centralized facilities addressed by these studies, the consensus is that the future supply chains would probably feature decentralized networks to reduce costs and improve efficiencies in the energy value per transport unit. Several studies (e.g. Ranta, 2005; Shi et al., 2008) investigate the logistic issues of a distributed system that utilize biomass, yet assuming rather simple usage scenarios and with little consideration on the biomass processing aspects. Second generation developments suggest the progression towards new platforms to produce fuels and power but also a clear potential in the integration of processing paths. To exploit the regional availability of feedstocks, decentralized centers would have to connect to the network adopting processing technologies as appropriate to their region.

A systems representation to handle a distributed network could use nodes for each processing centre, letting degrees of freedom for the capacity of each node and its processing technologies. Nodes could feature a different potential based on the local resources available, and their proximity to relevant industrial sites (i.e. petrochemical complexes), power stations, or urban and municipal sites (i.e. rendering opportunities to exploit waste streams).

As a special case, such representation could handle distributed biomass-to-liquid (BTL) platforms that produce second-generation biodiesel. The processing technologies include gasification and pyrolysis. Gasification can process a 
wide range of feedstocks (wood waste, agricultural waste, energy crops, and animal waste) but favors large capacities and, given the volumes needed, the cost of logistics is often prohibitive to run the gasification centrally. Bio-oil can provide the link, as pyrolysis units can be localized and the bio-oil is possible to move into bulk ships to a centralized facility. Using a network model, the location and the scale of the gasification and the pyrolysis units will be degrees of freedom to search with optimization, determining the best capacities and the best sites to use. Figure 7 illustrates a possible scenario produced by the solution of this hypothetical problem. In more complex cases, degrees of freedom could incorporate the optimal selection of processing technologies (e.g. those open to thermochemical as well as other processing pathways). Graph theory, optimization technology and general methods in operations research are welcome to tackle the complex and large problems, contributing with insightful recommendations to the development of business models.

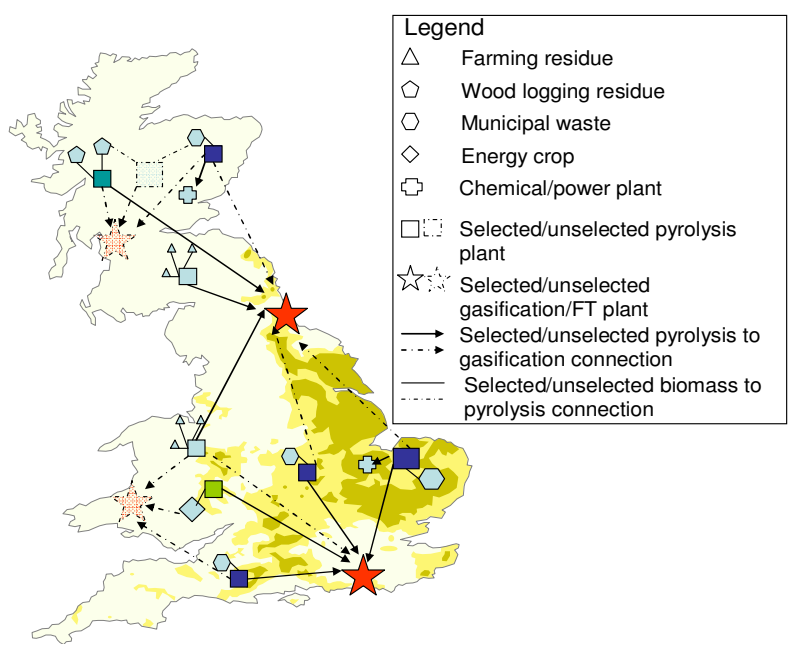

Figure 7. Illustrative BTL links and supply chains

\section{High-throughput analysis to support complex decision making}

\subsection{Developments beyond the second generation technology}

While $2 \mathrm{G}$ technology makes steady progress through several projects worldwide, there is already discussion about Phase III biorefineries (cf. Figure 8) that avoid any competition with food commodities. Unlike previous generations, there is no pre-occupation in the production of particular fuels (or even fuels at all) with the problem base expanding further in reference to feedstocks, fractionation paths and processes. Concerning feedstocks, the expanding base includes energy crops such as short rotating coppices (in EU-25 about 142 Mtoe, EEA report, 2006), embracing mineral raw materials (gas, crude oil, coal and lignite), waste bioproducts (biogas, municipal and agricultural waste), and aquatic biomass. Indeed, in the form of algae structures, the latter source accounts for the most promising biomass at the time of writing 
(Dismukes et al., 2008; Raja, et al., 2008). Requiring considerably less land use than terrestrial biomass, algal species can grow at mild conditions, offering much higher (solar) energy yields in comparison with terrestrial plants and the possibility to clean industrial $\mathrm{CO} 2$ emissions from flue gases and/or industrial and municipal wastewater. From a synthesis and design perspective, available processing options include closed culture systems (e.g. photosynthetic bioreactors or PBRs) and open ponds for massive algal production (cf. Borowitzka, 1999; Merchuk et al., 2007; Ugwu et al., 2008). Systems approaches to target the performance, design and optimize PBRs could rely on superstructure methods, drawing apparent analogies between temperature profiles and light utilization. The biomass produced from the culture of algae could follow the $2 \mathrm{G}$ pathways discussed previously but the design and the optimization of the supply chains would certainly need an alternative approach.

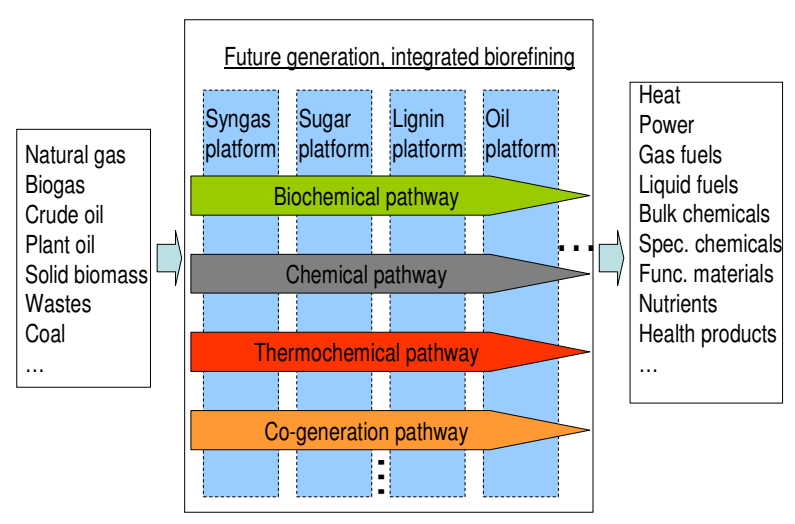

Figure 8. Integrated platforms-biorefineries

Rather than scoping for products and pathways, developments are important to further scope for common chemicals platforms suitable to share energy supplies and products between biorenfineries. As Phase III biorefineries assume no specific feedstocks and products, the synthesis problems remain open to all energy fuels and chemicals with choices for platforms among sugars, oils, syngas, and lignin. The oil and syngas platforms in particular represent a number of opportunities of processing biomass or biomass-derived intermediates by utilizing existing petrochemical facilities, such as oil cracking, hydrotreating, gasification, and chemical synthesis. The resulting products include gasoline, diesel, olefins, alcohols, acids, waxes, and many other commodity chemicals derivable from syngas. NREL and PNNL (Werpy et al., 2004, Holladay et al., 2007) produced an impressive list of potential building blocks, secondary chemicals, intermediates and products. The list demonstrates overwhelming similarities to the petrochemical industry, underlying the importance of the chemical engineering perspective in the developments. Corma et al (2007) reviewed the development in this area, with a focus on the products derived from heterogeneous catalysis. Hermann and Patel (2007) and Haveren et al. (2008) 
discussed the substitution of mineral feedstocks by renewable biomass components, offering suggestions that include ethylene, propylene, and glycol. With few exceptions, the production of intermediates and products features bewildering opportunities, presenting challenging problems for synthesis. Taking into account available techno-economic data and regional distributions of biomass, process systems methods can contribute with a more rigorous and systematic assessment of the suitable platforms.

\subsection{High-throughput testing using computer models}

The wide range of data and the multiple though parallel dimensions of analysis (e.g. the potential in processing different algal strains, the economic viability of particular platforms) set a colossal undertaking to the techno-economic studies, rendering flowsheeting too basic and a primitive option to choose unless in coordination and combination with other advanced methods. Such methods could link farming and renewables production and, subsequently, biomass analysis with biomass processing, stimulating demand for arable farming whilst reducing manufacturing impact on the environment. Process synthesis and conceptual programming can assess overall routings (global view), and the scope for integration between adjacent sites, processes and supply chains. Flowsheeting and optimization can evaluate design parameters of the supply chain (best technology), performance of unit operations (efficiency), operational aspects (reliability, flexibility, seasonality), and the cost efficiency of each venture.

The potential to coordinate different systems tools suggests the significance of an environment for high-throughput testing of ideas and processing technologies, gaining additional value in further collaboration with initiatives addressing strategic objectives (carbon footprints, LCA), and others focusing on the detailed analysis of processes (experimental investigation, detailed modeling, CFD modeling). Furthermore, the studies on biomass processing systems may be coordinated with those on the upstream systems, i.e. agricultural engineering. This would imply the integration of biomass processing models with the models of biomass production systems, rendering the potential for optimization or rational coordination over a longer value chain. In the course of pursuing the diverse types of integration, one would wish that developments produce an environment open to modeling or simulation software (probably using CAPE-OPEN standards) offering opportunities to experiment with alternative solution technologies, algorithms and decomposition techniques.

In the light of challenges posed by the biorefineries on one hand, and the merits and the capacities of the systems tools on the other, high-throughput testing can take the form of a Total Systems Approach, particularly with respect to process synthesis and design. The approach could support a holistic and structured way to understand and formulate problems in biorefineries, enabling a variety of solution methods and engaging links between different models. As illustrated in Figure 9, the approach could stratify problems formulated over different levels (scales), echoing similar multi-level and multiscale paradigms in the literature (Marquardt et al., 1999; Pantelides, 2001; Grossmann, 2004; Ingram, Cameron \& Hangos, 
2004). At the scale of a preliminary strategic investigation (or business conception), issues would address the regional planning and the evaluation of processing paths in combination with feedstock portfolios and logistics. Process development would target at the synthesis of flowsheets, the definition of products and the integration of units, whereas lower scales would develop unit parameters and operating conditions.

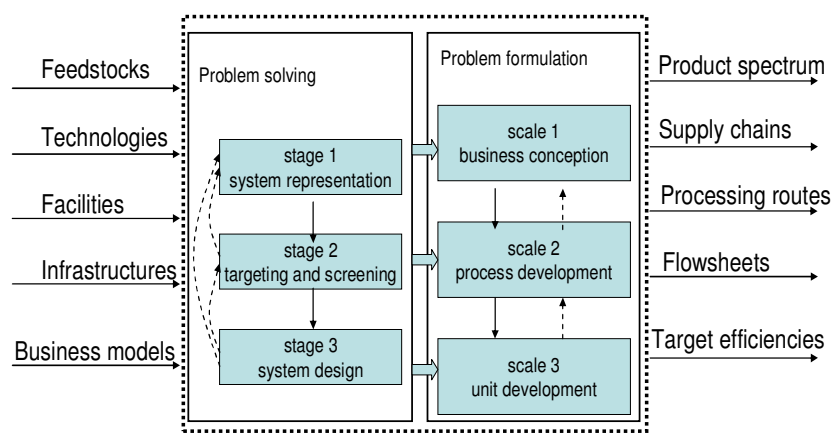

Figure 9. A total systems approach to biorefineries

To solve each problem the approach could employ a multi-stage procedure with screening and targeting stages (Linke and Kokossis, 2007) to precede the development of resourceful, economical, and inexpensive representations ready for optimization. Early stages could rely on concise and aggregate mathematical models, setting performance targets and reducing the space to search with the more detailed models. The above methodological framework, with possible adaptations, may be applied as a whole or in part by regional planning agencies and/or manufacturing companies with vested interest in the area.

Conventional design methods employed to develop processes for fossil-oil feedstocks have been using reliable fundamental knowledge from physico-chemical data and thermodynamic properties, reasonably established reaction mechanisms and kinetics, and/or reliable costing models. While new research is welcome and important to produce similar information for the biomass feedstocks, the techno-economic uncertainties and the lack of data in assessing biomass-based processes impel design methods to incorporate targeting and screening stages so as to systematically evaluate the impact of uncertainties in high volumes, determining profitable and promising lines of production while coping with limited availability of reliable knowledge. The layered approach advocated in this section outlines the methodological and technical components to tackle uncertainties using process systems engineering technology. Not replacing experiments, PSE technology is poised to complement experimental work, systematizing the search and offering a rational approach to innovative designs. 


\section{Conclusions}

As renewable systems have to match maximum efficiencies to compete with conventional processes, they could invariably benefit by the systematic use of optimization and modeling. However, in no other system is the potential of systems engineering more pronounced as in the design of biorefineries, an industrial concept uniquely attached to chemical engineering. Within its relatively short history, biorefining has developed into several generations. Rather than narrowing the scope for analysis, the biorefinery design becomes increasingly complex, as the degrees of freedom in the selection of feedstocks, the processing technologies and its various products continue to increase.

Systems engineering tools, particularly those in synthesis, optimization, and modeling could have a huge impact on the development of units, processes, supply chains, and the biorefinery concept itself. Principles of sustainable development probably preclude scenarios for global solutions but systems tools have the capabilities to analyze each problem separately. In the course of first generation biofuels, systems engineering demonstrated its potential largely through flowsheeting. Unless systems engineers take initiatives to bring forward advanced tools, the situation will not change. Advanced analysis could benefit by a methodological framework that, in the form of a systems platform, could support high-throughput testing, analysis, and computational experimentation using a total systems approach to combine multi-scale formulations with multi-stage problem solving, and building capabilities to tackle new problems with new methods, proving the power of systems engineering to support novelty and innovation.

\section{References}

Alva-Argáez A, AC Kokossis and R. Smith, (2007). A Conceptual Decomposition of MINLP models for the design of Water-Using Systems, Int. Journal of Envir. \& Pollution, 29 (1-3), pp 177-205.

Alva-Argaez A, AC Kokossis, and R Smith (2007). The design of water-using systems in petroleum refining using a water-pinch decomposition, Chem. Eng. Journal, 128 (1), pp33-46.

Alva-Argaez A, A. Vallianatos, and AC Kokossis (1999). A multi-contaminant transhipment model for mass exchange networks and wastewater minimisation problems, Comp. \& Chem. Eng., 23(10), pp1439-1453.

Audsley, E., Annetts, J. E. (2003). Modeling the value of a rural biorefinery--part I: the model description, Agricultural Systems, 76 (1), $39-59$.

Batterham, R. J. (2003). Ten years of sustainability: where do we go from here, Chemical Engineering Science, 58 (11), $2167-2179$.

Blasi, C. D. (2008). Modeling chemical and physical processes of wood and biomass pyrolysis. Progress in Energy and Combustion Science 34, 47-90.

Borowitzka , M. A. (1999). Commercial production of microalgae: ponds, tanks, tubes and fermenters. Journal of Biotechnology 70, $313-321$. 
BP (2008), BP Statistical Review of World Energy, June 2008 (available online) www.bp.com

BRAC (2006). Biofuels in the European Union - A Vision for 2030 and Beyond. The Biofuels Research Advisory Council, 14 March, 2006.

Bridgwater, T. (2007). Renewable transport fuels from biomass. Presented on International Biofuels Opportunities, Royal Society (UK), 23 \& 24 April 2007.

Bridgwater, T., A.V., Meier, D., Radlein, D. (1999). An overview of fast pyrolysis of biomass. Organic Geochemistry 30, $1479-1493$.

Briones V and AC Kokossis (1999). Hypertargets: a Conceptual Programming approach for the optimisation of industrial heat exchanger networks - I: Grassroots design and network complexity, Chem. Eng. Science, 54 (4), pp 519-539.

Briones V, and AC Kokossis (1999). Hypertargets: a Conceptual Programming approach for the optimisation of industrial heat exchanger networks - II Retrofit design, Chem. Eng. Science, 54 (4), pp 541-561.

Cardona, C.A., Sanchez O.J. (2006). Energy consumption analysis of integrated flowsheets for production of fuel ethanol from lignocellulosic biomass. Energy 31, 2447-2459.

Cardona C.A., Sanchez, O. J. (2007). Fuel ethanol production: Process design trends and integration opportunities. Bioresource Technology 98, 2415-2457.

Carlos A. Cardona, Óscar J. Sánchez (2007). Fuel ethanol production: Process design trends and integration opportunities. Bioresource Technology, 98 (12), 2415-2457

Chertow, M. R. (2004). Industrial Symbiosis, In: Cutler J. Cleveland, Editor(s)-in-Chief, Encyclopedia of Energy, Elsevier, New York, 2004, Pages 407-415.

CGR (2008). The integration of biofuels inside the refinery gate: implementation, logistics, and strategies. Study proposal, The Catalyst Group Resources, Inc., March 2008. Online available at http://www.catalystgrp.com/IntegrationOfBiofuels.html, accessed December 2008.

Clark, J. H. (2007). Green chemistry for the second generation biorefinery - sustainable chemical manufacturing based on biomass. J Chem Technol Biotechnol 82:603-609.

Corma, A., Iborra, S., \& Velty, A. (2007). Chemical routes for the transformation of biomass into chemicals. Chem. Rev., 107, 24112502.

Demirbas A. (2007). Progress and recent trends in biofuels. Progress in Energy and Combustion Science 33, 1-18.

Dimian, A. C. (2007). Renewable raw materials: chance and challenge for computer-aided process engineering. Computer Aided Chemical Engineering, 24, 309-318.

Dismukes, G.C., Carrieri, D., Bennette, N., Ananyev, G.M., Posewitz, M.C. (2008). Aquatic phototrophs: efficient alternatives to landbased crops for biofuels. Current Opinion in Biotechnology 2008, 19:235-240.

EIA (1999). Annual Energy Review, Energy Information Administration, 1999.

El-Halwagi, M. M.(1997). Pollution Prevention through Process Integration: Systematic Design Tools", Academic Press, San Diego. 
El-Halwagi, M., and Manousiouthakis V (1990). Automatic synthesis of mass exchange networks with single-component targets, Chem. Eng. Sci. 45(9), pp2813-2831.

El-Halwagi, M., and Manousiouthakis V (1990). Simultaneous synthesis of mass exchange and regeneration networks, AIChE J. 36(8), pp1209-1219.

El-Halwagi, M., and Srinivas B.K (1992). Synthesis of reactive mass exchange networks, Chem. Eng. Sci. 47(8), pp2113-2119.

Dustin Harell, H. Dennis Spriggs (2008). Targeting cogeneration and waste utilization through process integration. Applied Energy, In Press.

El-Halwagi, M. M. (2006). “Process Integration”, Elsevier, Amsterdam.

El-Halwagi, M., Dustin Harell, H. Dennis Spriggs (2008). Targeting cogeneration and waste utilization through process integration. Applied Energy, In Press.

Fernando S., Adhikari, S., Chandrapal, C., Murali, N. (2006). Biorefineries: Current Status, Challenges, and Future Direction. Energy \& Fuels, 20, 1727-1737.

Gassner, M, Marechal, F. (2008). Methodology for the optimal thermo-economic, multi-objective design of thermochemical fuel production from biomass, Computers \& Chemical Engineering, In Press.

Grossmann, I. E. (2004). Challenges in the new millennium: product discovery and design, enterprise and supply chain optimization, global life cycle assessment, Computers \& Chemical Engineering, 29, 29-39.

Gulati, M., Kohlman, K., Ladish, M.R., Hespell, R., Bothast, R.J. (1996). Assessment of ethanol production options for corn products. Bioresource Technology 5, 253-264.

Gunaratnam M., Alva-Argáez, A., Kokossis, A., Kim, J.-K. and Smith, R. (2005). Automated Design of Total Water Systems, Ind. \& Eng, Chem. Res., 44, pp 588-599.

Gundersen, T. and Naess, L. (1988). The Synthesis of Cost Optimal Heat Exchanger Network Configurations: An Industrial Review of the State of the Art, Comp. Chem. Eng, 12, pp503.

Gutierrez, L. F., Sanchez, O. J., Cardona, C. A. (2009). Process integration possibilities for biodiesel production from palm oil using ethanol obtained from lignocellulosic residues of oil palm industry, Bioresource Technology 100, 1227-1237.

Haas, M.J., Mcaloon, A.J., Yee, W.C., Foglia, T.A. 2006. A process model to estimate biodiesel production costs. Bioresource Technology. 97:671-678.

Hallale, N., Fraser, D.M. (1998). Capital cost targets for mass exchanger networks - a special case water minimization, Chem. Eng. Sci., 53(2), pp 293-313.

Haveren, J. v., Scott, E. L., Sanders, J. (2008). Bulk chemicals from biomass. Biofuels, Bioprod. Bioref. 2, 41-57.

Hermann, B.G., Patel, M.(2007). Today's and Tomorrow's Bio-Based Bulk Chemicals From White Biotechnology: A TechnoEconomic Analysis. Applied Biochemistry and Biotechnology 136, 361-388.

Holladay, J.E., Bozell, J.J., White., J.F., Johnson, D. (2007). Top Value-Added Chemicals from Biomass, Volume II: Results of Screening for Potential Candidates from Biorefinery Lignin, PNNL, October 2007. 
Huber, G. W., Iborra, S., \& Corma, A. (2006). Synthesis of transportation fuels from biomass: Chemistry, catalysts, and engineering. Chem. Rev., 106(9), 4044-4098.

Ingram, G. D. , Cameron, I. T., Hangos, K. M. (2004). Classification and analysis of integrating frameworks in multiscale modeling, Chemical Engineering Science 59, 2171-2187.

Kaylen, M., van Dyne, D. L., Choi, Y.-S., Blasé, M. (2000). Economic feasibility of producing ethanol from lignocellulosic feedstocks. Bioresource Technology, 72 (1), 19-32.

Kazantzi, V., El-Halwagi, M.M. (2005). Targeting material reuse via property integration, CEP, 101 (8), pp28-37.

Kazantzi, V., Qin, X., El-Halwagi, M., Eljack, F., Eden, M. (2007). Simultaneous Process and Molecular Design through Property Clustering- A Visualization Tool, Ind. Eng. Chem. Res., 46, 3400-3409.

Kempener, R. Beck, J., Petrie, J. (2007). Multi-scale modeling of bio-energy networks: a complex systems approach. European Congress of Chemical Engineering - 6, Copenhagen 16-21 September 2007.

Klatt K.-U., Marquardt, W. (2008). Perspectives for process systems engineering-Personal views from academia and industry. Computers and Chemical Engineering, in press.

Kokossis, AC (1993), Mathematical Programming Approaches in the Context of Process Integration, $10^{\text {th }}$ Annual Meeing, Process Integration Research Center, UMIST, UK

Kokossis, A.C., Floudas, C.A. (1990). Optimization of Complex Reactor Networks: 1. Isothermal Operation, Chem. Eng. Sci, 45 (3), pp595-614

Kokossis, A.C., Floudas, C.A. (1991). Synthesis of Isothermal Reactor Separator Recycle Systems, Chem. Eng. Sci., 46 (5-6), pp 13611683.

Linke, P., Kokossis, A.C. (2003, a). Attainable designs for reaction and separation processes from a superstructure-based approach. AIChE Journal 49(6), 1451-1470.

Linke, P., Kokossis, A.C. (2003, b). On the robust application of stochastic optimisation technology for the synthesis of reaction/ separation systems, Comp. \& Chem Eng, 27 (5), p.733-758.

Linke, P., Kokossis, A.C. (2004). Advanced process systems design technology for pollution prevention and waste treatment, Advances in Environmental Research, 8 (2), p.229-245.

Linke, P., Kokossis, A.C. (2007). A Multi-Level Methodology for Conceptual Reaction-Separation Process Design, J. Chem. Product and Process Modeling, 2(3), p1-42.

Marcoulaki, E.C., Kokossis, A.C. (1999), Scoping and screening complex reaction networks using stochastic optimization, AIChE J, 45(9), pp1977-1991.

Marcoulaki, E.C., Kokossis, A.C. (2000). On the development of novel chemicals using a systematic synthesis approach. Part I: Optimisation framework, Chem. Eng. Sci, 55 (13), pp 2529-2546.

Marcoulaki, E.C., Kokossis, A.C. (2001), On the development of novel chemicals using a systematic synthesis approach. Part II: Solvent design, Chem. Eng. Sci, 55 (13), pp 2547-2561. 
Marquardt, W., von Wedel, L., \& Bayer, B. (2000). Perspectives on lifecycle process modeling. In M. F. Malone \& J. A. Trainham (Eds.), Proceedings of the 5th international conference foundations of computer-aided process design, FOCAPD 1999, AIChE Symp. Ser. No. 323, Vol. 26 (pp. 192-214).

Merchuk, J. C. , Garcia-Camacho, F., Molina-Grima, E. (2007). Photobioreactor Design and Fluid Dynamics. Chem. Biochem. Eng. Q. 21 (4) $345-355$.

Mehta, V. L., Kokossis, A. (1997). Development of novel multiphase reactors using a systematic design framework, Computers \& Chemical Engineering, 21, S325-S330.

Mehta, V. L., Kokossis, A. (1998). New generation tools for multiphase reaction systems: A validated systematic methodology for novelty and design automation, Computers \& Chemical Engineering, 22, S119-S126

Nguyen, M. H., Prince, R. G. H. (1996).A simple rule for bioenergy conversion plant size optimisation: Bioethanol from sugar cane and sweet sorghum. Biomass and Bioenergy, 10(5-6), 361-365.

Pantelides, C. C. (2001). New challenges and opportunities for process modeling, In: Rafiqul Gani and Sten Bay Jorgensen, Editor(s), Computer Aided Chemical Engineering, Elsevier, Volume 9, Pages 15-26.

Papadopoulos, A.I., Linke, P. (2006, a). Efficient Integration of Optimal Solvent and Process Design using Molecular Clustering, Chem. Eng. Sci, 61 pp 6316-6336.

Papadopoulos, A.I., Linke, P. (2006), Multi-objective molecular design for integrated process-solvent systems synthesis. AIChE J. 52(3), 1057-1070.

Pfeffer, M., Wukovits, W., Beckmann, G., Friedl, A. (2007). Analysis and decrease of the energy demand of bioethanol-production by process integration. Applied Thermal Engineering 27, 2657-2664.

Piccolo, C., Bezzo, F. (2008). A techno-economic comparison between two technologies for bioethanol production from lignocellulose. Biomass and Bioenergy, In Press.

Ranta, T. (2005). Logging residues from regeneration fellings for biofuel production: GIS-based availability analysis in Finland. Biomass and Bioenergy 28, 171-182.

Raja, R., Hemaiswarya, S., Kumar, N. A., Sridhar, S., Rengasamy, R. (2008). A Perspective on the Biotechnological Potential of Microalgae. Critical Reviews in Microbiology, 34:77-88, 2008.

Riese J. (2006). Industrial Biotechnology -- Turning Potential into Profits. Plenary presentation, the third annual World Congress on Industrial Biotechnology and Bioprocessing, Toronto, July 11-14, 2006.

Sadhukhan, J., Mustafa, M.A., Misailidis, N., Mateos-Salvador, F., Du, C., Campbell, G.M. (2008). Value analysis tool for feasibility studies of biorefineries integrated with value added production. Chemical Engineering Science 63, 503-519.

Sammons, N., Eden, M., Cullinan, H., Perine, L., Connor, E. (2007). A flexible framework for optimal biorefinery product allocation. Environmental Progress, 26, 349-354.

Sendich, E. D., Dale, B. E., Kim, S. (2008). Comparison of crop and animal simulation options for integration with the biorefinery, Biomass and Bioenergy, 32, 1162-1174. 
Sikdar, S., El-Halwagi, M. M. (2001). Process Design Tools for the Environment, Taylor and Francis.

Shi, X., Elmoreb, A., Li, X., Gorenced, N. J., Jin, H., Zhang, X., Wang, F. (2008). Using spatial information technologies to select sites for biomass power plants: A case study in Guangdong Province, China. Biomass and Bioenergy, 32, 35-43.

Shah, P.B., Kokossis, A.C. (2002). New Synthesis Framework for the Optimization of Complex Distillation Systems, AIChE Journal, 48 (3), pp 527-550.

Shah, P.B., Kokossis, A.C. (2001), Knowledge based models for the analysis of complex separation processes, Comp. \& Chem. Eng., 25 (4-6), pp 867-878.

Smith, R. (2006), Chemical Process Design and Integration, Wiley, 2006.

Sokhansanj, S., Kumar, A., Turhollow, A. F. (2006). Development and implementation of integrated biomass supply analysis and logistics model (IBSAL). Biomass and Bioenergy 30, 838-847.

Ugwu, C.U., Aoyagi, H., Uchiyama, H.(2008). Photobioreactors for mass cultivation of algae. Bioresource Technology 99, $4021-4028$.

UOP (2005). Opportunities for biorenewables in oil refineries. Final technical Report to US Department of Energy, December 2005.

Werpy T., Petersen, G., Aden, A., Bozell, J., Holladay, J., White, J., Manheim, A. (2004). Top Value Added Chemicals From Biomass, Volume I: Results of Screening for Potential Candidates from Sugars and Synthesis Gas. NREL and PNNL, August 2004.

Wooley, R., Ruth, M., Glassner, D., Sheejan, J. (1999). Process design and costing of bioethanol technology: a tool for determining the status and direction of research and development. Biotechnology Progress 15, 794-803.

Wurzenberger, J. C., Wallner, S., Raupenstrauch, H., Khinast, J. G. (2002). Thermal Conversion of Biomass: Comprehensive Reactor and Particle Modeling. AIChE Journal, 48 (10), 2398-2411.

Zhang, Y.-H., Lynd, L. R. (2004). Toward an Aggregated Understanding of Enzymatic Hydrolysis of Cellulose: Noncomplexed Cellulase Systems, Biotechnology and Bioengineering, 88 (7), 797-824.

Wang, Y.P., Smith, R. (1994). Wastewater minimization, Chem. Eng. Sci, 49, p981.

Wang Y.P., Smith, R. (1994). Design of Distributed Effluent Treatment Systems, Chem. Eng. Sci, 49, p3127. 